\title{
Epidemiological study on children victims of dog bite in Campinas.
}

\author{
Ricardo M. Pereira, Andrea de Melo Alexandre Fraga, Raisa S. Uzun*.
}

\begin{abstract}
There is little information dog bite related trauma epidemiology in Brazil even though this is a frequent trauma in Emergency Unit and the most important cause for rabies transmission in humans. Most of the dog bites and the costs of its attendances and hospitalizations could be avoided through educative and preventive actions. We investigated how type of injury, bite location, age of the victim, dog's breed and the attacking dog correlate in a developing country. This study suggests that younger children are at high risk for injuries, the majority are bites on head, accidentally motivated by housed, healthy and familiar dogs. Educational awareness of people about the risk of dog bites and rabies is necessary. Parental education and supervision are the most important action to prevent severe dog bite injuries.
\end{abstract}

\section{Key words:}

Dog bite injury, pediatric trauma, epidemiology

\section{Introduction}

Children are a vulnerable group for dog attacks representing the majority of the victims from this trauma.[1] Consequences of these accidents include temporary lesions and permanent sequels, with pain, deformities, infections, psychological trauma, and absenteeism of school and work. [2] Epidemiologic data is important to understand risk factors and recommend public health actions to prevent morbidity and mortality related to this trauma mechanism. The objective of the study was to analyze and correlate epidemiologic dog bites data in pediatric patients at a developing country.

\section{Results and Discussion}

This was a retrospective descriptive study that included accidents with dogs occurred in the city of Campinas between 2011-2014. Victims were 0 to 14 years old, seen in person at the Pediatric Emergency Unit or assisted by telephone through the Poisoning Control Center from the University of Campinas General's Hospital. The data were analysed with EPI-INFO v7.2. 5604 animal contacts were reported from 2011-2014, 61\% were dog's accidents, $29 \%$ involving children and 412 met the inclusion criteria for the study. There were no difference in the cases in each year, and there were more cases on december (11\%) and august (10\%). 52\% of the cases were presential, while $41 \%$ were assisted by telephone. Most of the cases were attended during the afternoon and night, but that time of registration is not necessarily related to the time of the trauma. Regarding the age of the victims, the highest rate was between $5-9$ years old (33\%), followed by $10-14$ years old (29\%). The dog bites rates among boys and girls were $63 \%$ and $35 \%$, respectively. Considering the injured anatomic area, the highest rate was head and face (39\%), and lower extremities (25\%). Most of the cases were bites (95\%), multiple (65\%) and deep (84\%) injuries. The majority of the dogs was considered "mixed breed" (52\%), healthy (78\%) and housed (37\%). $65 \%$ of the animalchildren contact motivation were accidental, and $28,4 \%$ were provoked. The treatment most recommended was 10 day observation of the animal (82\%), and in $1 \%$ of the cases was suggested brain analysis of the dog. $12 \%$ of the victims received anti-rabies immunoglobulin prophylaxis and none of them had any reaction registered.

\section{Conclusions}

This is the first detailed study of dog bite injuries in Campinas (SP-Brazil) and one of the largest studies conducted in children in this country. The data suggest that younger children are at high risk for bites, and most of the cases are accidental, by housed, healthy and familiar dogs. The presence of a large number of stray dogs is a public health issue in this city. Increased educational awareness of people about the risk of dog bites and rabies is necessary. Parental education and supervision may be the most important action to prevent severe dog bite injuries.

\section{Acknowledgement}

This study was suportted by PIBIC/CNPq.

\footnotetext{
${ }^{1}$ Boat BW, Dixon CA, Pearl E, Thieken L, Bucher SE. Pediatric dog bite victims: a need for a continuum of care. Clin Pediatr (Phila). 2012 May;51(5):473-7.

2 Schalamon J, Ainoedhofer H, Singer G, Petnehazy T, Mayr J, Kiss K, et al. Analysis of dog bites in children who are younger than 17 years. Pediatrics. 2006;117:374-9.
} 